\title{
The effects of acupuncture on nausea and vomiting and consumption of propofol in cesarean section performed with spinal anesthesia
}

\author{
Ertugrul Kilic ${ }^{1 *}$, Mehmet Levent Uygur ${ }^{1}$, Murat Surucu${ }^{1}$, Ferdi Doganay ${ }^{2}$, Erhan Hafiz ${ }^{3}$
}

\begin{abstract}
Objective: The incidence of hypotension is $50-60 \%$ in obstetric surgeries. The most frequent comorbid clinical case of hypotention is nausea and vomiting. In addition, the probability of vomiting and nausea is very high in the period in which the peritoneum is holden after the birth of newborn. We wanted to observe the effects on nausea and vomiting occuring due to both spinal anesthesia and traction of peritoneum during caesarean section performed under spinal anesthesia by using conventional acupuncture techniques.

Material and Method: The study including 90 patients in the I-II risk groups of American Society of Anesthesiologists who will undergone caesarean section was planned. Acupuncture was performed for group A $(n=45)$ by using acupuncture needles from the $\mathrm{P} 6$ acupuncture point. Similar application was performed for group $\mathrm{P}(\mathrm{n}=45)$ by using acupuncture needles from a point $3 \mathrm{~cm}$ proximal to $\mathrm{P} 6$ point. In both practice, the needle was applied $20 \mathrm{~mm}$ depth of the skin and upholden for 30 minutes in the application area. Formation of nausea, vomiting and amount of propofol used was recorded for each patient.
\end{abstract}

Results: The observation rate of nausea and vomiting in the group A was significantly lower $(5,33(\mathrm{p}<0.05) ; 2,5(\mathrm{p}<0.05))$. Propofol consumption rate was also significantly lower $(4.6 \pm 11.7,63.0 \pm 9.4 \mathrm{mg}(\mathrm{p}<0.05))$.

Conclusion: The acupuncture applied perioperatively on P6 point in order to prevent nausea and vomiting in the cesarean section performed with spinal anesthesia is an effective method and also reduces the amount of propofol which will be used to prevent intraoperative vomiting.

Keywords: Acupuncture, cesarean, nause, vomit, propofol

\section{Introduction}

Cesarean section is performed frequently nowadays $(1,2)$. While large studies indicate the incidence of hypotension in spinal anesthesia in non-obstetric operations as $33 \%$, this ratio rises to $50-60 \%$ in obstetric surgeries and is more common than postoperative pain (3-5). The most frequent comorbid clinical case of hypotension is nausea and vomiting (6). In addition, the probability of vomiting and nausea is very high in the later phases of operations in the period in which the peritoneum is holding after the birth of newborn and clinical conditions causing by this can lead very serious side effects, including aspiration pneumonia (7-9). In addition, the amount of money spent for nausea and vomiting has been shown to be greater than those expended for postoperative analgesia (10).
Several studies in the literature generally focused on drug applications in order to prevent nausea and vomiting which are expected to be occurred in cesarean sections performed under spinal anesthesia $(1,2,7,11)$. The most preferred method for the prevention of nausea and vomiting occurring during cesarean section is administration of subhypnotic doses $(1 \mathrm{mg} / \mathrm{kg})$ of propofol $(7,11)$. However, the side effects that may occur due to the applications of these drugs should also be paid attention. We aim to stay away from these side effects by not using drugs.

Nei Guan (P6) point is located between the two tendons in both hands and inner forearm (flexor carpi radialis and palmaris longus) which is $2 \mathrm{~cm}$ away from the wrist (12). The practice of acupuncture for this region is performed for hundreds of years for the prevention of nausea and vomiting, treatment of carpal

\footnotetext{
Received: 05-01-2016, Accepted: 23-01-2016

${ }^{1}$ Sehitkamil State Hospital, Clinic of Anesthesiology and Reanimation, Gaziantep-Turkey

${ }^{2}$ Dr. Ersin Arslan State Hospital, Clinic of Anesthesiology and Reanimation, Gaziantep-Turkey

${ }^{3}$ Dr. Ersin Arslan State Hospital, Clinic of Cardiovascular Surgery, Gaziantep-Turkey

*Corresponding Author: Ertugrul Kilic E-mail: drertugrulkilic@yahoo.com Phohe: +90 5336304875
} 
tunnel syndrome and elimination of headache $(12,13)$. Many studies have focused on the effect of acupuncture done on P6 point on postoperative nausea and vomiting (13-16). Minimal adverse effects of this practice are discussed in very few studies $(6,17)$. These studies are on application of acupuncture with different stimulation methods and the techniques such as laser, electrical and manual applications are focused on $(17,18)$. In addition, the studies are usually on postoperative nausea and vomiting. We wanted to observe the effects on nausea and vomiting occurring due to both spinal anesthesia and traction of peritoneum during caesarean section performed under spinal anesthesia by using conventional acupuncture techniques.

\section{Material and Methods}

Our prospective, randomized, double-blind study was approved by the local ethics committee. Then, including 90 patients in the I-II risk groups of American Society of Anesthesiologist (ASA) between the ages of 18-40 who will undergo caesarean section was planned.

Patients were taken to preoperative regional anesthesia room, patients' oxygen saturation $\left(\mathrm{SaO}_{2}\right)$, noninvasive mean blood pressure (NIBP), heart rate (HR) and heart rhythm were monitored. Intravenous vascular access was opened with $22 \mathrm{G}$ branul and $0.09 \%$ sodium chloride was started as $5 \mathrm{~mL} / \mathrm{kg} / \mathrm{hr}$. Sedation was not implemented. Acupuncture was performed for group A $(n=45)$ by using acupuncture needles from the P6 acupuncture point. Similar application was performed for group $\mathrm{P}$ by using acupuncture needles from a point $3 \mathrm{~cm}$ proximal to P6 point where we were sure that no impact will occur for P6 point. In both practice, the needle was applied $20 \mathrm{~mm}$ depth of the skin and upholden for 30 minutes in the application area. All acupuncture practice was performed by the same anesthesiologist. The follow up of the patients were done by another anesthesiologist.

As follow standard during the operation, patients' NIBP, HR and saturations were monitored. Thirty $\%$ reduction according to baseline NIBP or reduction under 70 and more were considered as hypotension. Thirty \% reduction according to baseline HR or reduction under 65 and more were considered as bradycardia.

Formation of nausea and vomiting was recorded for each patient. Especially, the amount of propofol used to prevent vomiting of patients with feeling of nausea observing after clamping the umbilical cord of newborn was recorded by another anesthesiologist.

At the beginning of the study, power analysis was performed. Power application was determined to be $90 \%$ and $\alpha=0.05$. Results were assessed as median, mean $( \pm \mathrm{SD})$ and the number of patients. The exclusion criteria's of the study are identified as the patient's refusal to participating the study, chronic pain syndrome, hyperemesis gravidarum during pregnancy. Kolmogorov-Smirnov Z test (parametric data) was used for the normalization test. The Student-t test was used to compare parametric variables. Mann-Whitney was used to compare non-parametric variables. $\mathrm{P}<0.05$ was considered statistically significant. SPSS 15 (SPSS inc., Chicago, IL, USA) statistical analysis software was used for statistical analysis.

\section{Results}

The demographic data of patients, and intervention periods are given in Table 1. There was no statistically significant difference between demographic data of patients and their intervention periods.

Between groups, NIBP and HR monitoring are shown in Figure 1 and 2, respectively. There was no statistically significant difference in NIBP and HR monitoring between groups except the NIBP values 5 minutes after spinal anesthesia application. Considering the average value of the NIBP 5 minutes after the spinal anesthesia, the values were statistically significantly lower in group A $(72.6 \pm 5.5,75.26 \pm 5.6(p<0.05))$. In the same period, the rate of observation of hypotension was observed in 19 patients in group A (53.3\%) in 24 patients $(42.2 \%)$ in group $\mathrm{P}$ were observed. When considering all patients, this ratio was observed as 43 patients (47.7\%). During hypotension period that occurs after spinal anesthesia, 4 of our patients in group A had sense of nausea and vomiting was observed in only 2 patients. In the same period, sense of nausea was observed in 29 patients of group P, vomiting was observed in 27 patients (Table 2).

Nausea and vomiting observation rates between groups in patients in surgery after clamping the newborn's umbilical cord are given Table 2 . The observation rate of nausea and vomiting in the group A was significantly lower $(5,33(\mathrm{p}<0.05) ; 2,5$ $(\mathrm{p}<0.05))$. Propofol consumption rate was also significantly lower $(4.6 \pm 11.7,63.0 \pm 9.4 \mathrm{mg}(\mathrm{p}<0.05))$.

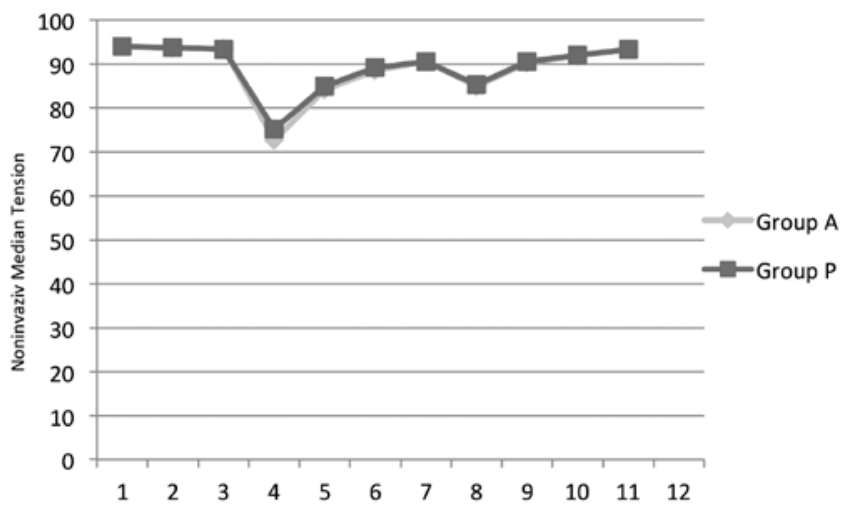

Figure 1. Non-invasive median tension 
Propofol use is given individually for each patient in Figure 3. Propofol was used for 7 patients in group A, propofol was needed for all patients in group P. Maximum $40 \mathrm{mg}$ propofol was used in consumption per person in group $\mathrm{A}$, this amount was observed as $84 \mathrm{mg}$ in group $\mathrm{P}$.

\section{Discussion}

We observed in our study that the preoperative P6 acupuncture application in caesarean section performed under spinal anesthesia reduced the nausea and vomiting caused by hypotension due to spinal anesthesia and/or nausea and vomiting occurring during the period of peritoneum clamping and the amount of propofol used in order to prevent nausea and vomiting in the period after the clamping of the umbilical cord of the newborn.

Hypotension observation rates and associated nausea and vomiting are common in cesarean section performed under spinal anesthesia $(4,19)$. In a study conducted by Voigt et al. (20), the incidence of hypotension in cesarean was identified as $46.2 \%$. Intra-operative nausea and vomiting rate was observed as $46.15 \%$ in the same study. The most commonly used method for the treatment of nausea and vomiting

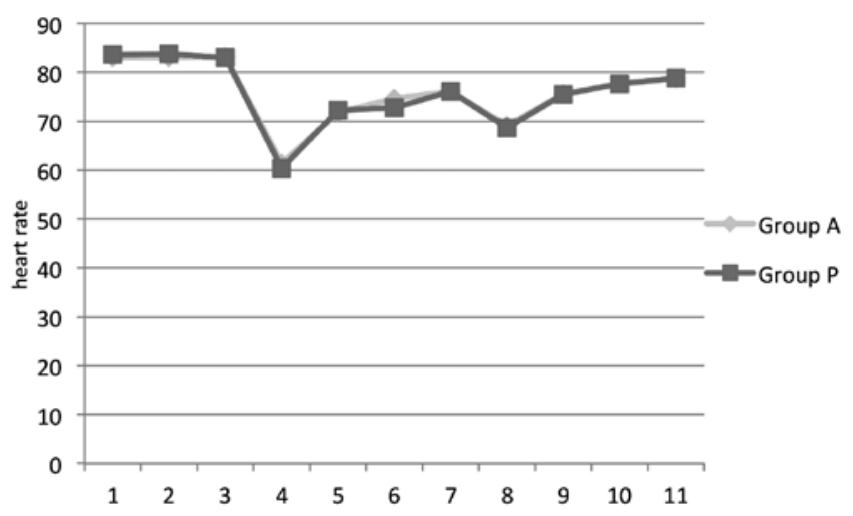

Figure 2. Heart rate between group $A$ and group $P$

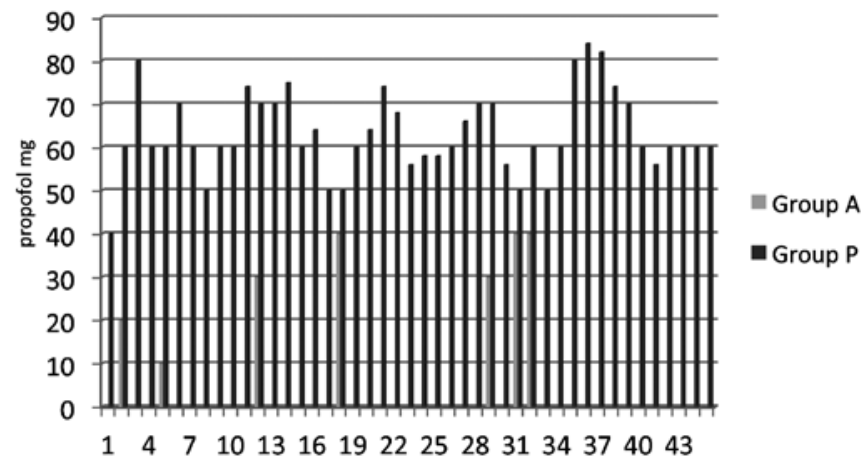

Figure 3. Propofol consumption (mg) per each patient observed due to hypotension formed by the effects of spinal anesthesia is the use of vasopressor medications, especially the use of ephedrine in order to prevent hypotension $(7,19)$. Considering the side effects of ephedrine used for the treatment of hypotension that occurs after spinal anesthesia in caesarean operations performed under spinal anesthesia, studies have been conducted to identify different doses of ephedrine or new drugs and techniques that can be used instead of ephedrine $(4,5,16,21)$. The positive effects of granisetron on nausea and vomiting were observed in a study conducted by Eldaba and Amr (5). It has been reported in a study conducted by Noroozinia et al. (1) that acupuncture applied on the P6 point had positive effects.

In our study, the incidence of hypotension after spinal anesthesia was $53.3 \%$ in the propofol group and $42.2 \%$ in the acupuncture group. Considering the total number, this rate is $47.7 \%$. Despite hypotension was observed more frequently in the acupuncture group, nausea was observed in only $4(8.8 \%)$ patients and vomiting occurred in $2(4.4 \%)$ of them. Considering the same period, the feeling of nausea was observed in 29 (64.4\%) patients in the propofol group and vomiting was observed in 27 $(60 \%)$ of these patients. It was observed that the acupuncture applied on the P6 point had no effect on the occurrence of

Table 1: Comparison of the demographic data of the groups

\begin{tabular}{|l|l|l|l|}
\hline & $\begin{array}{l}\text { Group I } \\
(\mathbf{n = 4 5 )}\end{array}$ & $\begin{array}{l}\text { Group II } \\
(\mathbf{n = 4 5 )}\end{array}$ & $\mathbf{p}$ \\
\hline Age (years) & 30.2 & 30.8 & 0.5 \\
\hline ASA physical status I/II & $28 / 18$ & $25 / 20$ & 0.6 \\
\hline Duration of surgery (min) & $32.7 \pm 2.4$ & $31.4 \pm 2.3$ & 0.8 \\
\hline
\end{tabular}

Data means \pm standard deviation or number of patient, there are no statistically significant differences between the groups, ASA: American Society of Anesthesiologists

Table 2: Incidence of number of nausea, vomiting and propofol consumption in groups. Data means \pm standard deviation or median

\begin{tabular}{|l|l|l|l|}
\hline & $\begin{array}{l}\text { Group A } \\
(\mathbf{n = 4 5 )}\end{array}$ & $\begin{array}{l}\text { Group P } \\
(\mathbf{n = 4 5 )}\end{array}$ & $\mathbf{p}$ \\
\hline $\begin{array}{l}\text { Number of nausea post } \\
\text { spinal anesthesia 5. min }\end{array}$ & 4 & 29 & 0.001 \\
\hline $\begin{array}{l}\text { Number of vomiting post } \\
\text { spinal anesthesia 5. min }\end{array}$ & 2 & 27 & 0.001 \\
\hline $\begin{array}{l}\text { Number of nausea after the } \\
\text { umbilical cord was clamped }\end{array}$ & 5 & 33 & 0.001 \\
\hline $\begin{array}{l}\text { Number of vomiting after the } \\
\text { umbilical cord was clamped }\end{array}$ & 2 & 5 & 0.001 \\
\hline $\begin{array}{l}\text { Total propofol consumption } \\
\text { (mg) }\end{array}$ & $4.6 \pm 11.7$ & $63.0 \pm 9.4$ & 0.001 \\
\hline
\end{tabular}


hypotension but was effective in the prevention of nausea and vomiting that can occur during the same period.

It was shown in many studies that the patient's mental status, the formation of hypotension, and traction of visceral peritoneum were effective in the observed occurrence of nausea and vomiting in caesarean section (22-24). It was observed in a study performed by Sane et al. (25) that the mixture of ondansetron and dexamethason administered intravenously 1-2 minutes after the clamping of newborn's umbilical cord was very effective to prevent nausea and vomiting of the mother in surgery that may occur after this period.

In our study, nausea was observed in $5(11.11 \%)$ patients and vomiting occurred in $2(4.44 \%)$ of them in the acupuncture treatment group. Nausea was observed in $33(7.33 \%)$ patients and vomiting occurred in $5(11.11 \%)$ of them in the propofol group. This situation indicates that the sub-hypnotic propofol use is an effective option to prevent vomiting that may occur due to the feeling of nausea especially caused by traction of visceral peritoneum after the clamping of the umbilical cord of newborns. We observed that the implementation of the P6 acupuncture that will be applied preoperatively reduced statistically significantly formation of the feeling of nausea and vomiting.

It has been shown in the study conducted by Numazaki and Fujii (26) that subhypnotic dose of propofol was very effective in preventing vomiting in nausea developing after the fetal umbilical cord clamping in cesarean section performed under spinal anesthesia. Fujii and Numazaki (11) have observed that increasing the dose of propofol did not make a difference in the prevention of vomiting.

Similarly in our study, nausea developed in 33 patients in propofol group, vomiting developed in only 5 of them with implementation of subhypnotic propofol. This shows that vomiting prevented in $84.8 \%$ of the patients that nausea developed and these rates are in line with the literature $(11,26)$. The amount of propofol for each patient was $4.6 \pm 11.7 \mathrm{mg}$ in the acupuncture group and $63 \pm 9.4 \mathrm{mg}$ in the propofol group and this shows that acupuncture application reduces the occurrence of nausea and vomiting and also the amount of propofol used in patients with nausea.

\section{Conclusion}

In conclusion, the acupuncture applied preoperatively on P6 point in order to prevent nausea and vomiting in the cesarean section performed with spinal anesthesia is an effective method and also reduces the amount of propofol which will be used to prevent intraoperative vomiting. We believe that our study needs to be confirmed with new studies.

\section{References}

1. Noroozinia H, Mahoori A, Hasani E, Gerami-Fahim M, Sepehrvand N. The effect of acupressure on nausea and vomiting after cesarean section under spinal anesthesia. Acta Med Iran. 2013;51:163-167.

2. Chattopadhyay S, Goswami S. Palonosetron prophylaxis for control of postoperative nausea and vomiting after cesarean delivery under spinal anesthesia. J Obstet Gynaecol India. 2015;65:28-33.

3. Macario A, Weinger M, Camey S, Kim A. Which clinical anaesthesia outcomes are important to avoid? The perspective of patients. Anesth Analg. 1999;89:652-658.

4. Arndt JO, Bömer W, Krauth J, Marquardt B. Incidence and time course of cardiovascular side effects during spinal anesthesia after prophylactic administration of intravenous fluids or vasoconstrictors. Anesth Analg. 1998;87:347-354.

5. Eldaba AA, Amr YM. Intravenous granisetron attenuates hypotension during spinal anesthesia in cesarean delivery: A double-blind, prospective randomized controlled study. J Anaesthesiol Clin Pharmacol. 2015;31:329-332.

6. Butterworth J. Physiology of spinal anesthesia: What are the implications for management? Reg Anesth Pain Med. 1998;23:370-373.

7. Tarhan O, Canbay O, Celebi N, Uzun S, Sahin A, Coşkun F, et al. Subhypnotic doses of midazolam prevent nausea and vomiting during spinal anesthesia for cesarean section. Minerva Anestesiol. 2007;73:629-633.

8. Norris MC. Spinal anesthesia for cesarean delivery. In: Norris MC, editor. Handbook of Obstetric Anesthesia. 5th ed. Philadelphia: Lippincott Williams and Wilkins; 2000. 309-312.

9. Allen TK, Habib AS. P6 stimulation for the prevention of nausea and vomiting associated with cesarean delivery under neuraxial anesthesia: A systematic review of randomized controlled trials. Anesth Analg. 2008;107:1308-1312.

10. Kerger H, Turan A, Kredel M, Stuckert U, Alsip N, Gan TJ, et al. Patients' willingness to pay for antiemetic treatment. Acta Anaesthesiol Scand. 2007;51:38-43.

11. Fujii Y, Numazaki M. Dose-range effects of propofol for reducing emetic symptoms during cesarean delivery. Obstet Gynecol. 2002;99:75-79.

12. Ezzo J, Streitberger K, Schneider A. Cochrane systematic reviews examine $\mathrm{P} 6$ acupuncture-point stimulation for nausea and vomiting. J Altern Complement Med. 2006;12:489-495.

13. Lee A, Fan LT. Stimulation of the wirst acupuncture point P6 for preventing postoperative nausea and vomitting. Cochrane Database Syst Rev. 2009:3281.

14. Gan TJ, Jiao KR, Zenn M, Georgiade G. A randomized controlled comparison of electro-acupoint stimulation or ondansetron versus placebo for the prevention of postoperative nausea and vomitting. Anesth Analg. 2004;99:1070-1075. 
15. Wang XQ, Yu JL, Du ZY, Xu R, Jiang CC, Gao X. Electroacupoint stimulation for postoperative nausea and vomiting in patients undergoing supratentorial craniotomy. J Neurosurg Anesthesiol. 2010;22:128-131.

16. El-Deeb AM, Ahmady MS. Effect of acupuncture on nausea and/ or vomitting during and after cesarean section in comparison with ondansetron. J anesth. 2011;25:698-703.

17. Agarwal A, Pathak A, Gaur A. Acupressure wristbands do not prevent postoperative nausea and vomiting after urological endoscopic surgery. Can J Anaesth. 2000;47:319-324.

18. Habib AS, Itchon-Ramos N, Phillips-Bute BG, Gan TJ; Duke Women's Anesthesia (DWA) Research Group. Transcutaneous acupoint electrical stimulation with the Relief Band for the prevention of nausea and vomiting during and after cesarean delivery under spinal anesthesia. Anesth Analg. 2006;102:581-584

19. Rasooli S, Moslemi F, Khaki A. Effect of sub hypnotic doses of propofol and midazolam for nausea and vomiting during spinal anesthesia for cesarean section. Anesth Pain Med. 2014;4:19384.

20. Voigt M, Fröhlich CW, Hüttel C, Kranke P, Mennen J, Boessneck O, et al. Prophylaxis of intra- and postoperative nausea and vomiting in patients during cesarean section in spinal anesthesia. Med Sci Monit. 2013;19:993-1000.
21. Hamzei A, Nazemi SH, Alami A, Davarinia Motlagh Gochan A, Kazemi A. Comparing different epinephrine concentrations for spinal anesthesia in cesarean section: A double-blind randomized clinical trial. Iran J Med Sci. 2015;40:302-308.

22. Schumann R, Polaner DM. Massive subcutaneous emphysema and sudden airway compromise after postoperative vomiting. Anesth Analg. 1999;89:796-797.

23. Apfel CC, Korttila K, Abdalla M, Kerger H, Turan A, Vedder I, et al. A factorial trial of six interventions for the prevention of postoperative nausea and vomiting. N Engl J Med. 2004;350:2441-2451.

24. Lussos SA, Bader AM, Thornhill ML, Datta S. The antiemetic efficacy and safety of prophylactic metoclopramide for elective cesarean delivery during spinal anesthesia. Reg Anesth. 1992;17:126-130.

25. Sane S, Hasanlui MV, Abbasivash R, Mahoori A, Hashemi ST, Rafiei F. Comparing the effect of intravenous dexamethasone, intravenous ondansetron, and their combination on nausea and vomiting in cesarean section with spinal anesthesia. Adv Biomed Res. 2015;4:230.

26. Numazaki M, Fujii Y. Subhypnotic dose of propofol for the prevention of nausea and vomiting during spinal anaesthesia for caesarean section. Anaesth Intensive Care. 2000;28:262-265.

Copyright $($ ) 2016 The Author(s); This is an open-access article distributed under the terms of the Creative Commons Attribution License (http://creativecommons. org/licenses/by/4.0), which permits unrestricted use, distribution, and reproduction in any medium, provided the original work is properly cited. All Rights reserved by international journal of Medical Science and Discovery. 